nique and concomitant RV outflow tract reconstruction in early infancy to achieve greater tricuspid valve and RV development for patients who cannot undergo successful catheter intervention. We believe that the postoperative tricuspid valve and RV can receive more venous return and have greater growth potential with this strategy than with simple valvotomy. If vital signs became unstable after test snaring of the interatrial communication, the communication should be left open. This strategy seems to be appropriate for patients with tripartite RV and tricuspid annulus larger than $60 \%$ of normal value without severe valvular dysplasia.

\section{References}

1. Rowlatt UF, Rimoldi HJ, Lev M. The quantitative anatomy of the normal child's heart. Pediatr Clin North Am. 1963;10:499-588.

2. Hanley FL, Sade RM, Blackstone EH, Kirklin JW, Freedom RM, Nanda NC. Outcomes in neonatal pulmonary atresia with intact ventricular septum. A multiinstitutional study. J Thorac Cardiovasc Surg. 1993; 103:406-27.

3. Pawade A, Capuani A, Penny DJ, Karl TR, Mee RB. Pulmonary atresia with intact ventricular septum: surgical management based on right ventricular infundibulum. J Card Surg. 1993;8:371-83.

4. Sano S, Ishino K, Kawada M, Fujisawa E, Kamada M, Ohtsuki S. Staged biventricular repair of pulmonary atresia or stenosis with intact ventricular septum. Ann Thorac Surg. 2000;70:1501-6.

\title{
The "clover technique" as a new approach for correction of postendocarditic severe tricuspid valve regurgitation
}

\author{
Georges Fayad, MD, ${ }^{a}$ Thomas Modine, MD, ${ }^{a}$ Pierre-Vladimir Ennezat, MD, ${ }^{b}$ Thierry Le Tourneau, MD, PhD, ${ }^{a}$ \\ Benoît Larrue, MD, ${ }^{a}$ Richard Azzaoui, MD, ${ }^{\text {a }}$ Olivier Nugue, MD, ${ }^{\mathrm{b}}$ Olivier Leroy, MD, ${ }^{\mathrm{c}}$ Christophe Decoene, MD, \\ Philippe Asseman, MD, and Henri Warembourg, MD, ${ }^{\text {a }}$ Lille and Tourcoing, France
}

\section{$\mathrm{V}$}

arious surgical treatments applied to tricuspid endocarditis provide immediate satisfactory results but seem to offer poor midterm results. We here report the use of the clover technique ${ }^{1}$ as a good alternative.

\section{Patient and Methods}

A 31-year-old male patient with a history of intravenous heroin addiction and active hepatitis $\mathrm{C}$ was admitted in a septic status with consciousness disorder and acute respiratory insufficiency.

A full-body scan revealed several pulmonary and splenic abscesses. Transesophageal echocardiographic findings showed massive vegetation on the mitral valve posterior commissure (Figure 1, $A$ ) with a grade II mitral valve incompetence. There were several vegetations on the tricuspid valve with a grade II leak. Hemocultures had revealed a meti-R Staphylococcus aureus. Intravenous antibiotic treatment with cefotaxime, fosfomycin, rifampicin, and fluconazole was initiated. A positive pulmonary and biologic outcome was observed rapidly. On the contrary, echocardiographic features worsened, with increasing mitral vegetation and grade IV mitral leak together with a grade IV tricuspid leak caused by total

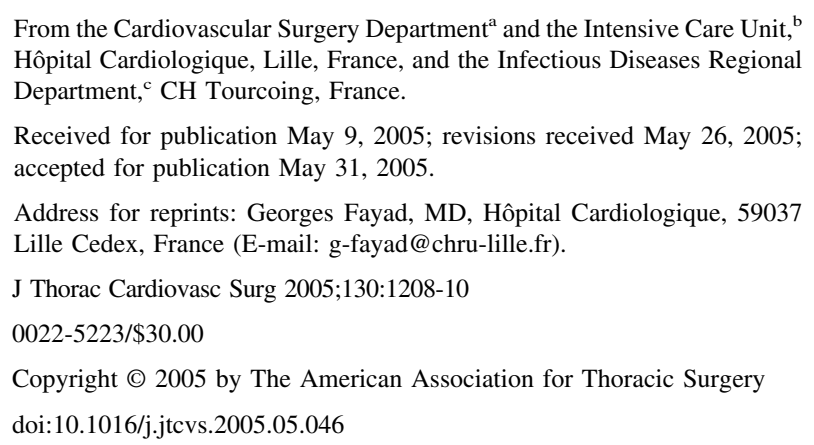

dehiscence of the anterior cusp. With respect to this development, we decided to operate.

The intervention was performed under extracorporeal circulation at $33^{\circ} \mathrm{C}$. The mitral valve was approached through a left atriotomy with resection of the posterior commissure and A3 and P3 sections and restoration of this area with a pericardial patch sutured to the posterior papillary muscle with a 4-0 polytetrafluoroethylene thread (Gore-Tex; W. L. Gore \& Associates, Inc, Flagstaff, Ariz), producing satisfactory results (Figure 1, B).

Analysis of the tricuspid valve confirmed dehiscence of the anterior cups and the absence of vegetations. We performed an annuloplasty according to the clover technique ${ }^{1}$ reinforced with an MC3 Edwards ring no. 36 (Edwards Lifesciences, Irvine, Calif; Figure 2).

Perioperative transesophageal echocardiography confirmed satisfactory results.

The postoperative course was uneventful, with continuation of the intravenous antibiotic treatment for 3 weeks, followed by oral delivery of rifampicin and pristinamycin (Pyostacine) for a further 3 weeks. The valve culture was sterile.

At the 6-month follow-up, the patient was in good general condition and in New York Heart Association functional class I, and no mitral or tricuspid leak was observed at echocardiography. Mean gradients were 6 and $4 \mathrm{~mm} \mathrm{Hg}$ for the tricuspid and mitral valves, respectively. An exercise test was carried out, confirming a good cardiovascular tolerance to effort.

\section{Discussion}

Tricuspid valve endocarditis benefits from antibiotic treatment with generally satisfactory results. ${ }^{2}$ Medical treatment is preferred because of the poor midterm results obtained with various surgical options. In this case report the surgical approach was considered 

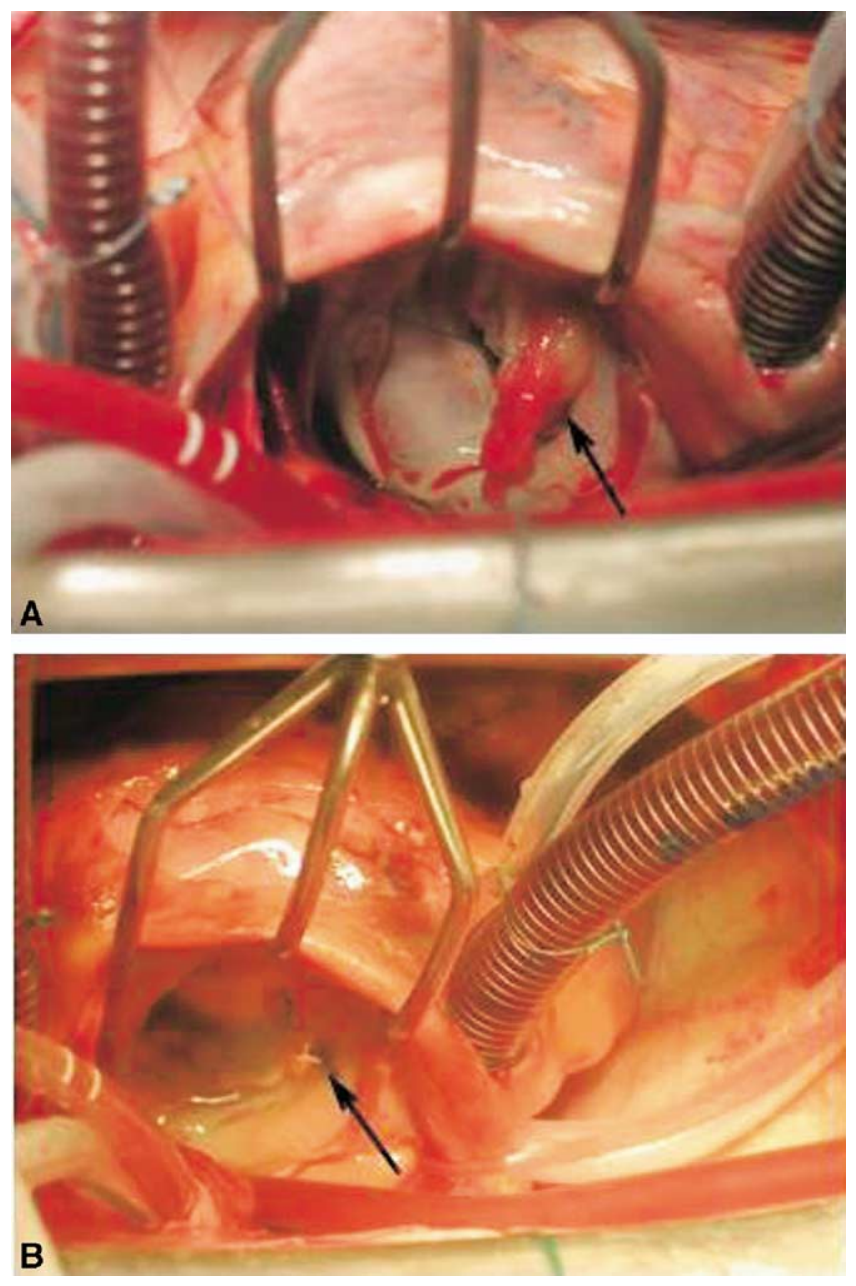

Figure 1. Mitral valve view. A, Massive vegetation on the posterior commissure. B, Restoration of the posterior commissure with a pericardial patch, with good competence.

because of major tricuspid incompetence associated with mitral endocarditis with very mobile voluminous vegetation.

Several technical possibilities are conceivable when facing such complex lesions. Arbulu and colleagues ${ }^{3}$ suggest a tricuspid valvulectomy without prosthetic replacement; however, late results are consistent with the development of severe right heart failure, with a frequent need for late reoperation. This technique's benefit is to cure the infection.

The second option is tricuspid prosthetic replacement. These prostheses are exposed to a serious infectious risk, as well as to dehiscence and thrombosis. ${ }^{4}$

Hence the use of mitral homografts ${ }^{5}$ as an alternative with mitigated results. Procurement difficulties and the need for an important surgical know how make this solution very difficult and nonreproducible.

On the contrary, the clover technique is an easy and reproducible technique. ${ }^{1}$ This procedure was described in case of tricuspid valve traumatic lesions. ${ }^{1,6}$ Native valve preservation offers a better resistance to infection.
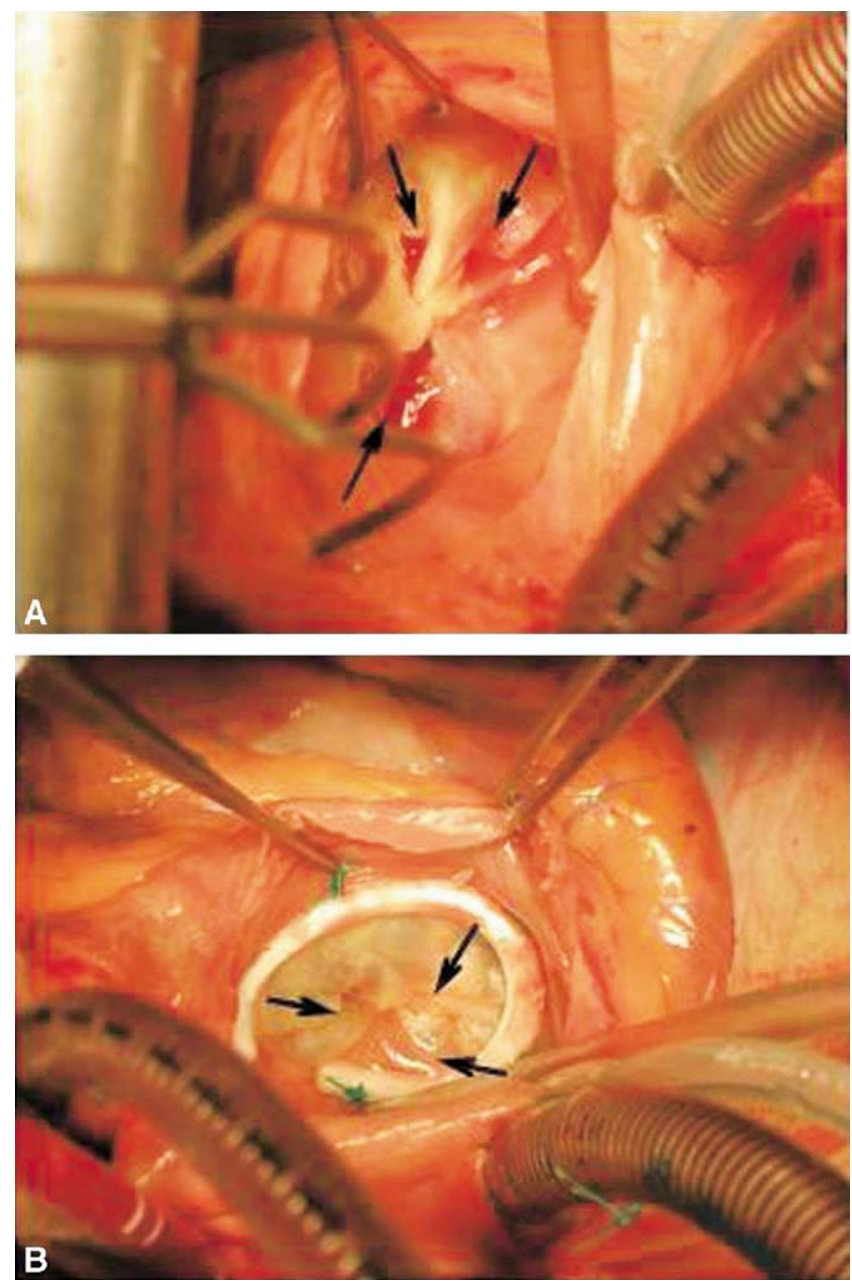

Figure 2. Tricuspid valve view. A, Clover technique. Arrows indicate the 3 functional orifices. B, A prosthetic annuloplasty ring was used, providing good competence.

We have already applied this technique in 3 cases of tricuspid endocarditis with complex lesions and obtained very satisfactory results. In these generally fragile patients, the clover technique seems a very good alternative. A long-term follow-up is obviously mandatory.

\section{References}

1. Alfieri O, De Bonis M, Lapenna E, Agricola E, Quarti A, Maisano F. The "clover technique" as a novel approach for correction of post-traumatic tricuspid regurgitation. J Thorac Cardiovasc Surg. 2003;126:75-9.

2. Hecht SR, Berger M. Right-sided endocarditis in intravenous drug users. Prognostic features in 102 episodes. Ann Intern Med. 1992;117:560-6.

3. Arbulu A, Holmes RJ, Asfaw I. Surgical treatment of intractable rightsided infective endocarditis in drug addicts: 25 years experience. J Heart Valve Dis. 1993;2:129-37.

4. McGrath LB, Gonzalez-Lavin L, Bailey BM, Grunkemeier GL, Fernandez J, Laub GW. Tricuspid valve operations in 530 patients. Twenty-five-year assessment of early and late phase events. J Thorac Cardiovasc Surg. 1990;99:124-33. 
5. Mestres CA, Miro JM, Pare JC, Pomar JL. Six-year experience with cryopreserved mitral homografts in the treatment of tricuspid valve endocarditis in HIV-infected drug addicts. J Heart Valve Dis. 1999;8: $575-7$.
6. Navia JL, Atik FA, Vega PR, Garcia M, Starling RC, GonzalezStawinski GV, et al. Tricuspid valve repair for biopsy-induced regurgitation in a heart transplant recipient. J Heart Valve Dis. 2005;14: 264-7.

\title{
Left main coronary artery atresia masquerading as dilated cardiomyopathy treated with aortic reimplantation
}

\author{
Ying-Jui Lin, MD, ${ }^{a}$ Chi-Di Liang, MD, ${ }^{a}$ Sheung-Fat Ko, MD, ${ }^{b}$ Chien-Fu Huang, MD, and
}

Jen-Ping Chang, MD, ${ }^{\mathrm{C}}$ Kaohsiung and Taoyuan, Taiwan

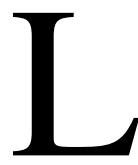

eft main coronary artery atresia (LMCAA) is rare, and only 19 pediatric patients with this lesion have been reported in the literature. ${ }^{1,2}$ Early diagnosis of LMCAA with aggressive surgical treatment is usually lifesaving. This report describes the case of a 7-year-old girl with LMCAA with heart failure that had been masquerading as dilated cardiomyopathy since infancy. The symptoms and signs completely resolved after coronary reimplantation.

\section{Clinical Summary}

A 7-year-old girl was seen with dyspnea and shortness of breath at the age of 4 months. A diagnosis of dilated cardiomyopathy with severe mitral regurgitation was made after initial echocardiographic study. After this diagnosis, she was treated with digoxin, furosemide, captopril, and aspirin, with stable condition. Followup echocardiography showed a dilated right coronary artery, but the ostium of the left main coronary artery was difficult to delineate. In addition, a reversed flow in the left coronary artery was demonstrated on color Doppler scan.

Cardiac catheterization revealed the pulmonary to systemic flow ratio at the pulmonary artery level to be 1.0. The left ventriculogram demonstrated a dilated and impaired left ventricle (ejection fraction 0.42), with moderate mitral regurgitation. The left coronary artery could not be selectively catheterized at either the aortic root or the pulmonary artery root. Right coronary angiography showed a dilated right coronary artery, with abundant collateral vessels draining to the left coronary artery. The patient

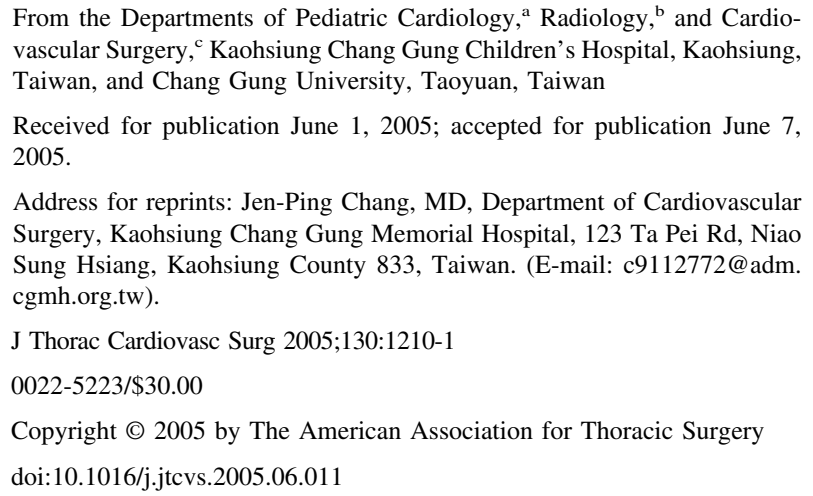

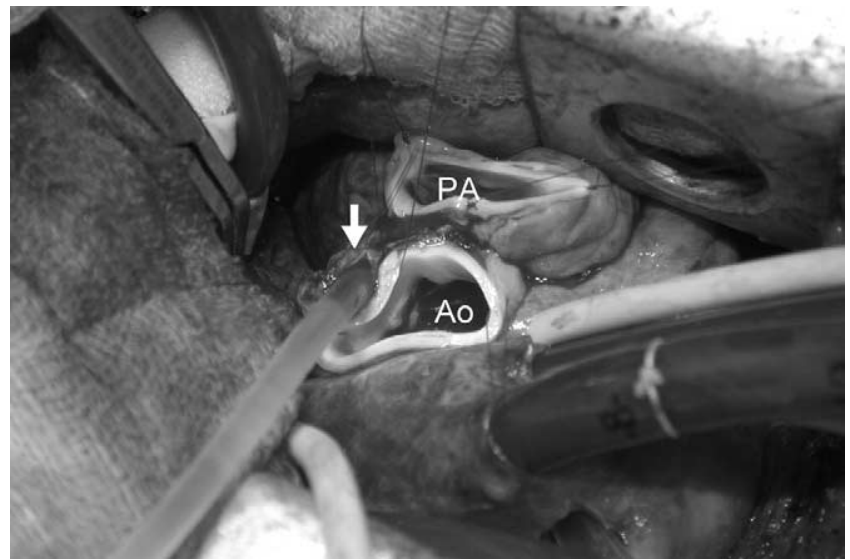

Figure 1. Intraoperative picture shows transected aorta $(\mathrm{Ao})$ and pulmonary artery (PA), without detectable left coronary orifice within. Arteriotomy was made on blind-ended left coronary artery, and coronary perfusion catheter was inserted for cardioplegic solution delivery (arrow).

was operated on for presumed LMCAA with moderate mitral regurgitation.

At operation, both great arteries were transected, and the absence of the left main coronary orifice in both aortic and pulmonary artery root was confirmed. The proximal left coronary artery was found to be intramural and blind ended (Figure 1). A diagnosis of LMCAA was established, and the left main coronary artery was subsequently reimplanted to the aortic root.

Three years after the operation, follow-up cardiac catheterization revealed a dramatic improvement in left ventricular function (ejection fraction 0.60), with significant regression of mitral regurgitation and right coronary dilation. Left coronary angiography revealed a widely patent reimplanted coronary artery (Figure 2).

\section{Discussion}

Most patients with LMCAA have symptoms, with failure to thrive and myocardial infarction during infancy and frequently syncope and tachyarrhythmias during childhood and adolescence. On extremely rare occasions, LMCAA may be asymptomatic. ${ }^{1,3}$ Includ- 